\title{
Ensaio sobre a relação epistemológica entre probabilidade e método científico
}

\author{
Essay on the epistemological relantionship \\ between probability and scientific method
}

Elvira Maria Godinho de Seixas Maciel 1

Fernando Salgueiro Passos Telles 2

\footnotetext{
1 Instituto Fernandes Figueira, Fundação Oswaldo Cruz.

Av. Rui Barbosa 716, 4 o andar, Rio de Janeiro, $R J$ 22250-020, Brasil. esmaciel@rio.nutecnet.br 2 Departamento de Epidemiologia e Métodos Quantitativos em Saúde, Escola Nacional de Saúde Pública, Fundação Oswaldo Cruz. Rua Leopoldo Bulhões 1480, 80 andar, Rio de Janeiro, $R J$ 21041-210, Brasil. nando@ensp.fiocruz.br
}

\begin{abstract}
In the XIX century, regularities in statistics of events were perceived in Medicine and Human Sciences. These regularities raised the possibility of forecasting what considered to be impredictable, and so, probabilistics laws became an alternative to the strictly-causal laws. This work presents a brief historical review of probability calculus and its applications. Some philosophical thoughs, regarding the use of probabilistics models and decision analysis in Medicine, are also discussed.

Key words Statistics; Probability; Decision Analysis; Medicine

Resumo No século XIX, as regularidades observadas na contagem dos eventos surgem como a possibilidade de previsibilidade do que parecia até então imprevisível, principalmente no campo das Ciências Humanas e da Medicina. As leis probabilísticas tornam-se uma alternativa para leis estritamente causais. Neste trabalho, fazemos um breve histórico do cálculo de probabilidades e suas aplicações, e desenvolvemos algumas questões filosóficas acerca da utilização da teoria da probabilidade e da análise de decisão - oriunda do campo econômico - à Medicina. Palavras-chave Estatística; Probabilidade; Análise de Decisão; Medicina
\end{abstract}




\section{Introdução}

Em 1844, Quételet afirma que um grande número de atributos humanos distribuem-se de forma graficamente semelhante à curva de Gauss. Medidas dos aspectos físicos mais freqüentes caracterizariam o homem médio. Introduz-se, assim, um novo tipo de informação sobre populações e uma nova concepção de como controlá-las (Hacking, 1995). A descrição de regularidade na distribuição dos caracteres ganha estatuto de lei biológica e social. Assistimos, em meados do século XIX, à polêmica entre Claude Bernard, fisiologista e defensor da medicina experimental, crítico do uso da estatística e da idéia de média como expressão da norma biológica, e os partidários da estatística e do uso do cálculo de probabilidades em medicina. Dentre estes últimos havia duas correntes distintas: os que privilegiavam a estatística e o estudo da freqüência de doença nas populações, no sentido de observar a associação de eventos - entre eles Pinel - e os que sugeriam o uso da probabilidade como forma de avaliar e controlar a confiabilidade da correspondência entre sinal, sintoma e lesão (Canguilhem, 1994).

Os objetivos deste ensaio são basicamente três: fazer uma introdução geral à problemática da probabilidade para sanitaristas; apontar questões epistemológicas acerca do uso da probabilidade na medicina contemporânea e desenvolver a hipótese de que o aumento progressivo da influência da epidemiologia na pesquisa clínica acaba por aproximar, na produção de conhecimento em medicina, as noções de teoria científica e conhecimento de senso comum.

\section{Observações sobre a teoria da probabilidade}

A ciência clássica, cujo paradigma é a mecânica newtoniana, buscava leis naturais, imutáveis, eternas. Um universo perfeito no qual a imprevisibilidade e, portanto, a existência do acaso seriam frutos dos limites do homem. A evolução de sistemas aparentemente imprevisíveis poderia ser calculada pela inteligência ilimitada do Deus de Laplace. A desordem é mera aparência. $\mathrm{O}$ acaso e a probabilidade destinam-se, então, a dissimular a ignorância.

No século XIX, as regularidades observadas na contagem dos eventos surgem como a possibilidade de alguma previsibilidade do que parecia até então imprevisível, principalmente no campo das ciências humanas e da medicina. Os dados recolhidos serviram fartamente à aplicação do cálculo de probabilidades. As leis probabilísticas tornam-se uma alternativa para leis estritamente causais; leis humanas tão poderosas quanto as naturais. A natureza humana é substituída pelo homem normal (Hacking, 1995).

Cotidianamente levamos em conta nossos riscos. Proteger-se da morte, da doença, do mau êxito nos negócios não é uma invenção recente. Há relatos de seguros para embarcações e proprietários de escravos já na Grécia do século II a.C. (Levy \& Roth, 1936). A prática de evitar riscos sempre esteve associada à possibilidade da ocorrência de eventos nefastos.

A teoria da probabilidade, no entanto, é relativamente recente. Há diversas formas de enumerar as condições históricas do desenvolvimento do cálculo de probabilidades. Evidentemente, este se deu em contexto complexo que não deve ser simplificado em um único evento. Entretanto, achamos curiosa e digna de nota a proposição de Du Pasquier (1926) de que o impulso ao desenvolvimento dos estudos sobre a probabilidade parece ter se devido, entre outras coisas, ao fato de a aristocracia européia, sobretudo nos países católicos, ocupar grande parte do seu tempo nos jogos de azar. $\mathrm{O}$ primeiro registro de um estudo desse tipo é do século XVII, anterior a 1642 (Du Pasquier, 1926). É um trabalho de Galileu intitulado Considerazione sopra il Giuoco dei Dadi, encomendado por um nobre italiano. O problema era: um jogador lança três dados; se a soma é superior a dez, ele ganha; se a soma é igual ou inferior a dez, ele perde. E as perguntas: quais as chances de ganhar ou perder e quais as combinações mais prováveis. Alguns anos mais tarde, Pascal recebe de um aristocrata francês, Chevalier de Mére, uma solicitação semelhante. Uma partida de dados envolvendo dois jogadores, com o máximo de cinco lances, deverá cessar quando um deles completar três pontos. O prêmio para o vencedor é de 16 francos. Se a partida precisa ser interrompida antes de haver um vencedor, como dividir o prêmio? Pascal envia a Fermat o enunciado do problema e ambos chegam simultaneamente, embora por métodos distintos, a soluções semelhantes. Fermat desenvolve um método baseado em análise combinatória, aplicável à interrupção de qualquer partida, com qualquer número de jogadores. O cálculo de probabilidades tem aí o seu primeiro método geral e torna-se uma disciplina matemática.

Na segunda metade do século XVII, na Inglaterra e na Holanda, a probabilidade ganha um sentido diferente. Desde o ano de 1592, após terem sido atingidos por uma epidemia, 
os ingleses mantiveram o hábito de sistematizar obituários; as paróquias publicavam pouco antes do natal uma lista de todos os óbitos ocorridos naquele ano. Baseando-se nessas listas, John Graunt propôs um método para determinar a mortalidade provável em qualquer idade. Trabalhos na mesma linha foram realizados, na mesma época, por Jean Hudde e Edmond Halley. Todavia, mais de meio século se passaria antes que o cálculo de probabilidade tivesse o seu valor reconhecido. No século XVIII seus postulados passam a ser aplicados sobre os dados estatísticos com a finalidade de revelar a existência de causas regulares que explicassem a ocorrência e a freqüência dos eventos. A probabilidade torna-se, então, um método universal, uma "lógica geral da incerteza" (Du Pasquier, 1926).

Laplace teve um papel significativo na ampliação do campo de uso da probabilidade (Du Pasquier, 1926). Ele teria demonstrado no Essai Philosophique sur les Probabilités que a probabilidade aplica-se a questões fundamentais relativas à vida dos indivíduos e das nações:

"As questões mais importantes da vida são em sua maioria problemas de probabilidade! Nós podemos mesmo dizer, falando rigorosamente, que quase todos os nossos conhecimentos só são prováveis; e no pequeno número das coisas que nós podemos saber com certeza, nas próprias ciências matemáticas, os principais meios de chegar à verdade, à indução e à analogia são fundados sobre as probabilidades, de sorte que o sistema inteiro dos conhecimentos humanos se liga a esta teoria" (Laplace, 1814, apud Du Pasquier, 1926:23).

Este argumento de Laplace salienta um importante problema epistemológico suscitado pela incorporação da Teoria de Probabilidades ao cotidiano da ciência. Trata-se dos dois sentidos em que o termo - probabilidade - pode vir a ser apreendido.

O primeiro, formal, refere-se à sua expressão matemática, isto é, representa a freqüência relativa de um elemento numa determinada série. Não é, como é fácil depreender, um conceito empírico; não diz respeito a uma pretensa realidade factual; não é sintético, é analítico. O segundo é empírico, indutivo, partindo do conjunto de casos particulares rumo à construção de universais que possibilitem a predição. Explicaremos melhor: com Kant podemos situar o conhecimento justamente na fronteira, na interface, entre análise e síntese. Há um empirismo necessário ao conhecimento. Kant afirma a importância da experiência como o início de todo e qualquer conhecimento. No entanto, promove sua "revolução copernicana" ao pon- tuar a supremacia do sujeito na delimitação daquilo que é possível conhecer, isto é, o fenômeno. Ao dar o estatuto de fenômeno à realidade configurada na faculdade do entendimento, este filósofo cria um peculiar dualismo no qual o foco situa-se na relação entre o mundo e o pensamento. Escapa, portanto, de um racionalismo dogmático de conceitos a priori fundados num suposto pensamento verdadeiro, divino, mas também não é levado pelo empirismo que pressupõe uma verdade oculta a ser desvelada numa natureza também divina.

Aqui aproximamos a idéia de síntese e de experiência de mundo. A inferência elaborada com base em qualquer tipo de análise sempre será excedente com relação à mesma. É que elementos tais como "tudo" e "sempre", no momento em que se referem à predição de estados de coisas no mundo, excedem a observação que lhes deu origem. Aceitamos, neste trabalho, a existência de uma dimensão puramente matemática para o conceito de probabilidade, que é exclusiva da ordem do pensamento, isto é, que funciona como modelo de inferência na relação entre sujeito e objeto. Por exemplo, a Lei dos Grandes Números é uma proposição lógica da qual lançamos mão quando queremos predizer comportamentos em grandes séries empíricas. Nada obriga, entretanto, que a realidade comporte-se sempre conforme um enunciado matemático. A adequação da situação empírica em questão ao enunciado a que atribuímos poder de inferência sobre esta terá sempre um caráter hipotético.

A compreensão do conceito de probabilidade como contendo uma dimensão numérica e outra não numérica é defendida por Popper (1993:161-162):

"Começarei distinguindo duas espécies de enunciados de probabilidade: aqueles que não enunciam uma probabilidade em termos de números e aqueles que a enunciam em termos de números - e que denominarei enunciados de probabilidade 'numérica'.

Assim, o enunciado 'A probabilidade de conseguir onze com dois dados (não viciados) é 1/8' seria um exemplo de um enunciado de probabilidade numérica. Os enunciados de probabilidade não numérica abrangem várias espécies. 'É muito provável que obtenhamos um líquido homogêneo misturando água e álcool' ilustra uma espécie de enunciado que, através da interpretação adequada, poderia, talvez, transformar-se num enunciado de probabilidade numérica. (Por exemplo 'A probabilidade de obter... é muito próxima de 1'). Uma espécie muito diferente de enunciado de probabilidade não numérica seria, por exemplo: 'É altamente im- 
provável a descoberta de um efeito físico que contradiga a teoria quântica'; esse enunciado, creio eu, não pode ser transformado em enunciado de probabilidade numérica ... sem sofrer distorção de significado".

No segundo sentido do termo - não numérico -, este ganha o estatuto de predição relacionada ao mundo físico. "Provável” agora significa expectativa com relação a um acontecimento futuro, expectativa que pretende estar fundada na observação e análise de séries de eventos passados que comportaram-se tal qual um determinado modelo formal.

Indiscutivelmente, Laplace coloca-nos diante de um dos impasses mais importantes do conhecimento objetivo, que é o da necessidade de justificar uma crença a respeito da realização de um acontecimento futuro. Dentre as várias características do pensamento moderno podemos destacar a busca de uma solução não dogmática para dar conta desta questão. No século XVIII, por exemplo, Hume chama a atenção para o fato de que no mundo físico não encontramos qualquer dispositivo que justifique inferir um acontecimento futuro valendo-se de observações pregressas. Neste sentido, a inferência indispensável às demandas cotidianas seria possibilitada - mas não justificada - pela crença ou fé de que eventos futuros tenderão a ser semelhantes aos do passado. Mecanismo psicológico a que Hume denominou "hábito". A inferência causal não se justificaria, portanto, pela experiência observacional. Como resolver o problema de justificar racionalmente o conhecimento depois da crítica humeana escapando, ao mesmo tempo, de epistemologias fundadas em princípios dogmáticos? Ainda que o pensamento de Hume não seja, por definição, epistemológico, uma vez que a noção de hábito apenas descreve os modos de entendimento humano, fugindo da idéia de qualquer tipo de fundamentação, sua filosofia não deixa de dificultar a aceitação de sistemas de leis científicas.

Kant parte das idéias de Hume para elaborar a "Crítica da Razão Pura" (Kant, s/d), em que tenta tornar viável a justificativa do conhecimento racional ao fundar o conceito de "juízo sintético a priori”. Popper apóia em Kant o seu pensamento. Outros filósofos, no entanto, justamente por julgarem problemática a idéia de uma síntese $a$ priori, vão ter na Teoria da Probabilidade o solo epistêmico a partir do qual justificarão o conhecimento objetivo, como o fizeram os empiristas lógicos do Círculo de Viena, no início do século XX. Mas, neste caso, isto só poderá ser feito se os dois sentidos do termo - provável - acima referidos, forem sobrepostos.
Laplace, ao fundir os dois sentidos num único, parece antecipar o papel do cálculo de probabilidades na ciência contemporânea. As decisões baseadas em lógicas como a bayesiana ou a nebulosa, por exemplo, aceitam como legítima a indiferenciação dos conceitos de probabilidade formal e empírica, incorporando e evidenciando a dimensão subjetiva no uso da probabilidade.

$\mathrm{Na}$ inferência fundamentada no cálculo de probabilidades, a certeza é a unidade e a probabilidade uma fração. Esta quantificação deriva da definição clássica de probabilidade matemática: a probabilidade matemática de um evento é igual à razão entre o número de casos favoráveis e o número total de casos. Quando aplicado a uma situação cuja evolução deve-se predizer, temos uma totalidade de casos possíveis, tanto favoráveis quanto desfavoráveis. Os casos possíveis referem-se ao futuro, enquanto o número total de casos, na proposição matemática, tem sempre o presente como limite. Assim é que na inferência probabilística relativa a uma situação empírica, podemos perceber a junção do atual com o virtual, apoiada num certo tipo de racionalidade subsumida pela matemática e a ela subordinada.

Os sistemas dinâmicos da mecânica newtoniana caracterizam-se pelas idéias de determinismo, causalidade e reversibilidade do tempo. Dado o conhecimento da posição e da velocidade de um corpo num momento determinado pode-se deduzir a sua evolução, tanto no passado, quanto no futuro. O demônio imaginado por Laplace é capaz de observar estas condições para todos os corpos do Universo. Ele recorreu a esta descrição de forma a realçar o limite das possibilidades do conhecimento humano e de nossa capacidade de predição. Daí a necessidade de, diante dessa inevitável ignorância, atributo da condição humana, recorrer a uma descrição estatística de certos processos. A dualidade lei-condições iniciais põe em xeque a descrição determinística, objetiva, da dinâmica clássica, acessível apenas ao demônio de Laplace (Prigogine \& Stengers, 1991). Na linguagem da dinâmica, um sistema evolui sobre uma trajetória determinada, guardando as condições iniciais que determinam essa evolução. Na termodinâmica, os sistemas fora do equilíbrio evoluem para um mesmo estado de equilíbrio, independentemente de suas condições iniciais; o que conta é a bacia atrativa: todos os sistemas com um atrator pertencente a esta bacia possuem o mesmo ponto de equilíbrio, dirigindo-se, portanto, para o mesmo estado final. Estávamos diante da abertura para uma ciência do complexo. Alguns investi- 
gadores apostavam que para articular as duas descrições - dinâmica e termodinâmica - seria necessário reduzir a complexidade dos fenômenos termodinâmicos à simplicidade de comportamentos elementares, o que implicava a passagem do nível macroscópico para o microscópico. Boltzmann foi o primeiro a enfrentar esse desafio (Prigogine \& Stengers, 1991). A inovação conceitual necessária localizou-se no conceito de probabilidade: esta deveria transformar-se de uma forma de aproximação em um princípio explicativo.

Com Cournot teria sido iniciada uma nova fase no uso das probabilidades (Du Pasquier, 1926). Para Laplace o acaso era conseqüência das limitações do conhecimento humano e, diante de uma inteligência superior, todas as condições, causas e, portanto, a evolução de quaisquer sistemas seriam reveladas. Assim, o acaso definido como desconhecimento das causas era inassimilável em um sistema determinista, a antítese da aplicação de qualquer lei. Para Cournot, ao contrário, o acaso é uma realidade objetiva independente do estágio dos nossos conhecimentos. Trata-se agora de definir noções precisas de medida - dadas pela teoria moderna dos conjuntos - e a axiomatização, pela da aritmética, da teoria. No início do século XX, com uma base lógica irretocável e fundado nas idéias de Cournot, o cálculo de probabilidades já não é "uma lógica geral da incerteza, mais metafísica do que matemática" (Du Pasquier, 1926:30).

\section{A lei dos grandes números e a inferência estatística}

A Lei dos Grandes Números ou Lei Empírica do Acaso compreende três noções fundamentais: a freqüência relativa, a flutuação e a ausência de regularidade. Ao propô-la, o objetivo de Jacques Bernoulli não era demonstrar a realidade da referida lei, comprová-la empiricamente, mas criar um sistema teórico explicativo.

Imaginemos um evento E. São executadas n tentativas de realização do evento E. O número de vezes que o evento E realiza-se nessas n tentativas é sua freqüência absoluta. Para sabermos se esse evento é ou não raro, é necessário calcular sua freqüência relativa. A freqüência relativa do evento $\mathrm{E}$ é o número de vezes em que este realizou-se - k - em relação ao número total de tentativas $-\mathrm{n}$. A freqüência relativa é sempre um número compreendido entre 0 e 1 .

A freqüência de um mesmo evento varia com o número de tentativas. Diferentes séries compreendendo o mesmo número $\mathrm{n}$ de tentativas, nas mesmas condições, podem apresentar diferentes freqüências relativas. Pela experiência sabemos, no entanto, que a freqüência relativa para uma certa classe de fenômenos, em condições bem definidas, tende a oscilar em torno de um certo número p, que coincide com a probabilidade matemática do evento estudado. Além disso, a experiência ensina que quanto maior o número de repetições, mais a freqüência relativa aproxima-se da probabilidade matemática, limite para o qual tende a freqüência relativa em um número indefinido de repetições.

Tomando-se por base a lei dos grandes números, a probabilidade matemática anunciase como a seguir:

"Em uma série de tentativas repetidas um grande número de vezes nas mesmas condições, quaisquer dos acontecimentos fortuitos possíveis manifestam-se com uma freqüência relativa sensivelmente igual à sua probabilidade matemática. A aproximação aumenta em geral muito rapidamente, à medida que as tentativas tornam-se mais numerosas" (Du Pasquier, 1926:76).

A diferença entre a freqüência relativa do evento e sua probabilidade matemática constitui o afastamento relativo da série. Com o aumento do número de tentativas, o afastamento relativo tende para 0 .

Ao aplicar os teoremas do cálculo de probabilidade aos eventos, recorremos a um movimento de aproximação semelhante àquele realizado quando aplicamos a objetos reais as leis mecânicas do movimento. Não há uma justificativa para a afirmação "ao lançarmos um dado perfeito 600 vezes, a face contendo o número 1 aparecerá 100 vezes voltada para cima", já que há outras possibilidades. No entanto, pressupomos que os teoremas do cálculo de probabilidades aplicam-se com uma certa aproximação aos fenômenos naturais que repetem-se em condições quase idênticas. A teoria probabilística determina a probabilidade matemática, que é um conceito, enquanto a prática requer a previsão de freqüências de eventos. Jacques Bernoulli evidenciou esta distinção entre abstração e realidade na aplicação do cálculo de probabilidades.

Uma nova abordagem para o problema da inferência estatística foi dado por Thomas Bayes, na primeira metade do século XVIII (Bernstein, 1996). O seu problema formulava-se de forma distinta do proposto por Bernoulli: dado o número de vezes que um evento desconhecido ocorreu ou não, qual a probabilidade de que ele aconteça em uma única tentativa? Nesse 
caso, nada sabemos do evento, exceto que ele ocorreu um certo número de vezes e não ocorreu em um outro número de vezes. Bayes utiliza o exemplo das bolas de bilhar. Uma bola de bilhar está parada sobre a mesa. Uma segunda bola é impulsionada. O sucesso ocorre quando esta vai localizar-se à direita da primeira; se esta pára à esquerda, considera-se fracasso. Alguém conta os sucessos e fracassos. Qual a probabilidade de o lançamento seguinte obter sucesso? No método bayesiano, a probabilidade de a bola localizar-se à direita é, a cada tentativa, reformulada em função do resultado obtido na tentativa anterior - cada lançamento tem uma probabilidade prévia e uma probabilidade posterior. Há, assim, uma revisão contínua das inferências ao agregarem-se novas informações. A análise bayesiana pode ser utilizada em processos de tomada de decisão durante a realização de um diagnóstico clínico, por exemplo. Do mesmo modo, a lógica nebulosa utiliza-se de dados a priori para tomada de decisão. Estes dados são sistematizados numa matriz composta por elementos cujas qualidades e valores relativos são inferidos por causa de conhecimento prévio e especializado. Assim é que, no nosso entender, a lógica nebulosa otimiza o princípio bayesiano ao permitir que se trabalhe com a valoração de eventos simultâneos, muitas vezes contingentes, que passam a ser indicadores mais efetivos para a predição de um desfecho em questão. É o a priori, aqui forjado em linguagem matemática. Não nos deve causar estranhamento o fato de que os mencionados tipos de lógica passem a ter sua importância aumentada pelo desenvolvimento da informática.

\section{Probabilidade e senso comum}

Uma questão que agora gostaríamos de apresentar é: em que medida o uso da probabilidade em tomadas de decisão pretensamente científicas, do ponto de vista da epistemologia, não passa de uma instrumentalização de nossos sentidos em favor do conhecimento de senso comum? Definiremos, a seguir, o que consideramos senso comum e o que queremos dizer com "tomadas de decisão pretensamente científicas".

O racionalismo platônico constitui-se num dos primeiros sistemas de pensamento a destacar um certo tipo de dualismo inerente ao conhecimento. Isto fica bem caracterizado pela separação estabelecida entre o que podemos apreender pela percepção do mundo físico daquilo que realmente conhecemos pela razão.
Aqui, a percepção mediada pelos órgãos dos sentidos é uma espécie de ruído a interferir com o verdadeiro conhecimento. A razão, que tem a capacidade de contemplar as essências por meio da lembrança ou reminiscência da alma, deve abdicar daquilo que há de mundano e, portanto, enganoso, no que nos chega pela sensação do mundo físico. Platão enuncia uma questão epistemológica crucial, que é a de que há componentes do conhecimento cuja fonte não pode ser encontrada na experiência do mundo físico; são entes do pensamento, cuja realidade é apenas formal.

"Sócrates: - Que diremos então de certas coisas, Símias? Da justiça, por exemplo? Diremos que é alguma coisa ou nada?

Símias :-Diremos que é algo.

Sócrates: - Não o diremos também do bom e do belo?

Símias :-Sem dúvida.

Sócrates:-Entretanto, já chegaste a vê-los com teus olhos?

Símias :-Nunca.

Sócrates: - Há algum sentido corporal pelo qual chegaste a apreciar as coisas de que te falo, como a grandeza, a sanidade, a força, em resumo, a essência de todas as coisas, isto é, aquilo que são nelas mesmas? Ou se aproximará mais do fim desejado aquele entre nós que se encontre em maior grau e mais precisamente preparado para pensar por si mesmo a coisa que observa e toma por objeto? ...

... - Deste princípio - disse Sócrates - não se segue que os filósofos devem pensar e dizer: a razão deve seguir apenas um caminho em suas investigações, enquanto tivermos corpo e nossa alma estiver absorvida nesta corrupção, jamais possuiremos o objeto de nossos desejos, isto é, a verdade. Porque o corpo nos oferece mil obstáculos pela necessidade que temos de sustentá-lo e as enfermidades perturbam nossas investigações..." (Platão, 1996:127).

Assim, para Platão, a Reminiscência é o lugar do conhecimento verdadeiro e inequívoco, justamente por esta perseverar independentemente das vicissitudes da percepção do mundo físico. Numa outra passagem famosa, no Menon, Sócrates demonstra a realidade do conhecimento das essências pela Reminiscência da alma, ao fazer com que um escravo compreenda um determinado teorema da geometria, sabendo de antemão que o mesmo jamais tivera entrado em contato com tal disciplina até então. Para Platão isto só se torna possível pelo fato de o escravo trazer em sua alma (razão) a reminiscência de tal conhecimento desde a eternidade.

Mas talvez haja uma outra alternativa para explicar a bem sucedida preleção de Sócrates 
para com o escravo. Podemos aqui substituir a idéia de Reminiscência pela de conhecimento de senso comum. Conforme Guerreiro (1999), Platão poderia ter explicado o sucesso de Sócrates por meio de três fatores relacionados diretamente com as capacidades humanas e o uso da linguagem e da razão no processo de obtenção do conhecimento: a clareza e a precisão daquele que faz a demonstração; a capacidade de dedução inerente ao discernimento humano como uma potencialidade podendo ser ativada desde de que adequadamente estimulada; e "o caráter auto-evidente dos axiomas apresentados cuja veracidade pode ser apreendida intuitivamente por todo e qualquer ser humano dotado de uma capacidade mínima de discernimento" (Guerreiro, 1999:12).

Aqui apresentamos o conceito de senso comum composto por duas dimensões: a primeira relativa à idéia de percepção; a segunda da ordem do entendimento. Haveria, portanto, uma experiência sensível e uma conseqüente elaboração mental comuns relativas, por assim dizer, à própria condição humana. Percepção e entendimento de senso comum seriam, então, o a priori a partir do qual uma outra forma de conhecimento especulativo - científico - encontraria o solo fértil para o seu desenvolvimento. Aqui seguimos bem de perto a noção popperiana de que o conhecimento científico seria estruturado como conjecturas, passíveis de falseamento pelo trabalho experimental, conjecturas nascidas no solo do senso comum. Talvez possamos nos atrever a afirmar que noções como percepção e entendimento de senso comum aproximam-se das idéias kantianas de intuição de espaço e tempo e de suas respectivas sistematizações na instância da imaginação. A estética transcendental, intuição do espaço e do tempo, responderia por nossa capacidade humana comum de perceber, ficando o entendimento de senso comum por conta da sistematização de tais aspectos da sensibilidade na instância da imaginação, a serviço do que Kant chama "faculdade do entendimento". Note-se bem que aqui não estamos querendo especular sobre um suposto conceito de senso comum em Kant. Longe disto, pretendemos apenas estabelecer aproximações entre aquilo que o mencionado filósofo expõe como condição necessária, embora não suficiente, à apreensão do mundo físico, isto é, o espaço e o tempo como dimensões da existência humana, e a idéia de uma percepção e entendimento comuns, necessários às demandas elementares de nossa existência. Kant cria um sistema filosófico no qual funda a possibilidade da experiência das coisas e dos estados de coisas no fa- to de que os objetos ocupam um lugar no espaço e de que o tempo passa tendo o sujeito como referência. É justamente pelo fato de tempo e espaço deixarem de ser apreendidos como grandezas em si mesmas e passarem a constituir dimensões essenciais da existência, que pensamos poder aproximá-las da idéia de senso comum aqui definida. Trata-se, portanto, de uma relação de proximidade que pretendemos estabelecer entre senso comum e as intuições de espaço e tempo em Kant. Sabemos que, embora qualquer tipo de apreensão da realidade pelo entendimento deva estar subsumida às intuições transcendentais de tempo e espaço, isto não ocorre de maneira direta. O sensível torna-se inteligível no ato de um certo enquadramento elaborado na "imaginação", ou seja, a forma do fenômeno é dada na Faculdade do Entendimento. Neste caso, haveria coisas do mundo a meio caminho entre o sentido e o compreendido, na “imaginação”. Esta apresenta seus elementos ao entendimento para que este imponha-lhes a forma. A síntese produzida pela imaginação poderia, então, conter os elementos de um conhecimento comum. É claro que, do ponto de vista kantiano, o termo "conhecimento" é aqui inadequado, pois só se conhece com base na forma atribuída ao sensível (objeto) feita pela Faculdade do Entendimento. Do ponto de vista da filosofia de Kant, não haveria propriamente objetos na síntese da imaginação, mas arriscamo-nos a especular acerca de alguns elementos aí existentes que, em seu conjunto, caracterizariam uma certa experiência comum: percepção e entendimento de senso comum (sem confundir o termo "entendimento" com a Faculdade do Entendimento). Seriam noções como as de "outro", "múltiplo", “dentro", “fora”, “todo”, “parte”, por exemplo, que nos parecem, valendo-se da topografia kantiana do entendimento humano, estarem mais próximas da intuição de espaço e de tempo do que estariam as categorias da Faculdade do Entendimento. Já a idéia de "causa”, por exemplo, teria gênese mais identificada com a especulação das categorias da Faculdade do Entendimento do que com as séries espaço-temporais da imaginação, mesmo que saibamos que sem as idéias de "antes" e de "depois” não há, evidentemente, especulação causal possível. Se partirmos da epistemologia de Popper, de raízes kantianas, o pensamento científico é a passagem deste primeiro plano para o segundo, isto é, das noções menos equívocas proporcionadas pela síntese espaço-temporal rumo à especulação. A ciência estaria, então, em continuidade com o senso comum, e a diferença entre eles estaria no "locus" ocupado 
por cada um na estruturação do fenômeno e não na hierarquização referida à verdade.

Cabe ressaltar o caráter hipotético de nossas reflexões acerca das relações entre as inferências lógico-matemáticas, a ciência e o senso comum. Compreendemos que tais inferências, justamente pelo grau de objetividade que lhes é peculiar, aproximam-se muito mais de um conhecimento imediato e menos sujeito ao equívoco do que a especulação científica. Dito de outra maneira, por mais complexos que sejam os cálculos e artifícios matemáticos que um determinado software aplique para melhor classificar os dados da realidade a ser estudada (a distribuição espaço-temporal de um fenômeno mórbido numa população, por exemplo), as inferências produzidas terão um conteúdo maior de observação que de reflexão.

Ousamos afirmar que estas técnicas desenvolveram-se de tal maneira que encontra-se reduzido o espaço para a dimensão metafísica do conhecimento. As teorias matemáticas aqui apresentadas seriam próteses tão eficazes do senso comum que reduziriam a necessidade do conhecimento que não o do imediatamente dado. Estaríamos testemunhando a derrocada do ideal de ciência conjectural, retratado pelo falibilismo popperiano?

Acreditamos que falar das noções atuais de probabilidade e lógica leva invariavelmente à discussão da natureza da ciência contemporânea quanto às suas supostas faces metafísica e objetiva; a primeira mais próxima, em nosso entender, do ideal especulativo e conjectural popperiano e a segunda mais afinada com a inequivocidade almejada pelo conhecimento de senso comum.

\section{Informação e decisão}

Passemos agora a alguns exemplos de situações em que o raciocínio probabilístico vem sendo aplicado, a fim de que o leitor possa julgar a pertinência das teses aqui expostas.

Imaginemos o caso de um paciente com hipertensão arterial severa de início recente cuja etiologia precisa ser definida. São levantadas três hipóteses: estenose da artéria renal, glomerulonefrite auto-imune e feocromocitoma. De acordo com a história clínica e o exame físico, mesmo antes do início da realização de exames complementares, cada uma destas hipóteses tem uma certa probabilidade de estar correta - probabilidade anterior ou pré-teste. $\mathrm{O}$ bom teste diagnóstico é aquele capaz de alterar significativamente a probabilidade das hipóteses em questão. Está em jogo, permanen- temente, ao considerar-se as probabilidades pré e pós-teste a relação custo-benefício da intervenção proposta.

Nem todos os eventos prestam-se a investigações estocásticas. Para que o cálculo de probabilidades possa ser aplicado aos fenômenos, suas freqüências relativas, quando o número de tentativas ou observações é considerável, deve obedecer à lei de Gauss ou lei dos erros - representada na curva binomial cuja função é informar a probabilidade de um dado erro ou afastamento da probabilidade matemática ocorrer. Infelizmente, esta não é a realidade de grande parte dos fenômenos biológicos, o que traz alguns problemas para o cotidiano da clínica.

Atualmente, em diversas áreas, convivemos com a exigência de que as decisões sejam simultaneamente mais ágeis e melhor fundadas, fato que pressupõe um razoável conhecimento e gerenciamento dos riscos envolvidos. Podemos definir, neste caso, o risco como algo decorrente da incerteza de acertar ou errar e, conseqüentemente, alcançar êxito ou fracasso (Guerreiro, comunicação pessoal).

$\mathrm{Na}$ astronomia, na economia, assim como na medicina baseamo-nos na crença da regularidade de certos eventos. Tal regularidade, contudo, varia conforme o campo de conhecimento em que nos encontramos. Quaisquer predições realizadas devem levar em conta o fato de que as variáveis que intervêm no processo estão sujeitas a sofrerem modificações relevantes. Quanto maior o controle destas variáveis, maior o grau de acerto da previsão e, portanto, menor o risco envolvido nas decisões a ela relacionadas. Podemos, assim, estabelecer uma escala de graus de risco. Acreditamos que o grau de risco das previsões relacionadas com ações físicas, como por exemplo na astronomia, é consideravelmente menor do que as relacionadas com a ação humana (Guerreiro, comunicação pessoal).

As ações humanas envolvem fatores tais como a finalidade visada, as alternativas disponíveis, as probabilidades pró e contra, e as decisões ou escolhas. Ao configurarmos uma situação de escolha, são levados em conta os aspectos subjetivos, que são aqueles ligados ao agente no ato da escolha e os aspectos objetivos, constituídos pelo leque de alternativas disponíveis.

Como identificar a decisão correta e o momento oportuno de tomá-la? Ao admitirmos que graus variáveis de risco estão presentes em todos os tipos de decisões, como conviver com isto? A relação da tomada de decisão com o gerenciamento dos riscos encaminha estas ques- 
tões. A idéia de relação custo-benefício, oriunda da área econômica, alastrou-se por diversas áreas, de modo que as noções de custo e benefício têm sido amplamente utilizadas na ação humana em geral (Guerreiro, comunicação pessoal). Em medicina, estas traduzem-se como efetividade. Um tratamento é efetivo se traz mais benefício que prejuízo quando prescrito (Fletcher et al., 1996). A eficácia de um determinado procedimento legitima-se mediante uma conclusão obtida num estudo epidemiológico experimental ou observacional. A efetividade trata da valoração da aplicação de técnicas diagnósticas ou terapêuticas cuja eficácia está demonstrada. A preocupação agora é com o resultado final, quando é levada em consideração a associação de fatores outros não contemplados no estudo de eficácia. Infelizmente, grande parte dos estudos em epidemiologia é de eficácia e não de efetividade. Por exemplo, o uso continuado de ácido acetil salicílico em doses baixas previne, conforme demonstram estudos de eficácia, a doença obstrutiva coronariana em populações de risco. Porém, a efetividade desta medida é questionável, na medida em que outros estudos nestas mesmas populações apontam para o maior risco de acidente vascular encefálico hemorrágico, como conseqüência do uso crônico do mencionado medicamento, provavelmente por seu conhecido efeito anti-coagulante.

Há várias teorias acerca da aplicação na tomada de decisão, do cálculo de probabilidade. Guerreiro (comunicação pessoal) considera a teoria subjetivista ou personalista de Ramsey e Finetti como a de maior utilidade para a aplicação na análise de riscos. Segundo esta teoria, o grau de probabilidade favorável ou desfavorável depende mais da capacidade do agente em identificar e comparar opções do que das alternativas existentes; logo, uma boa decisão está muito mais relacionada à capacidade de análise e bom senso do que de cálculo:

"Em outras palavras: caso se admita uma adequada quantificação de probabilidades, esta mesma quantificação pressupõe necessariamente uma 'análise qualitativa'. Nesta o que está em jogo fundamentalmente é a acuidade e o bom senso do analista. Entre outras coisas, isto permite compreender a razão pela qual um analista mais perspicaz é capaz de vislumbrar quatro alternativas onde outro só vislumbra duas e é capaz de distribuir os graus de probabilidade das alternativas vislumbradas de um modo mais preciso do que o outro faria, supondo que ambos tenham o mesmo grau de conhecimento técnico relativo à análise quantitativa" (Guerreiro, 1999:14).
A intuição, o bom senso, a capacidade de análise de situações parecem desempenhar papéis cruciais nas tomadas de decisão. As teorias probabilísticas, por mais eficientes e formalmente precisas que sejam, não são adequadas para a aplicação direta em situações de caráter prático.

Cremos que quanto mais informação detivermos, maiores as chances de tomarmos uma boa decisão. A probabilidade tem sido a base de muitas das decisões tomadas atualmente. Decisões políticas, sobretudo aquelas ligadas à área econômica, adquirem um ar de objetividade se são cientificamente, probabilisticamente, fundadas. Ou na medicina, ao conferirmos maior credibilidade às decisões assistidas ou prescritas por sistemas especialistas. Ao reduzirmos a tomada de decisão ao manuseio metódico da informação, facilmente concluiremos que um computador será capaz, se lhe forem fornecidos os dados, de escolher melhor.

Não podemos desconsiderar tanto o valor teórico quanto o poder do conhecimento probabilístico em orientar decisões. Informações oriundas do campo da epidemiologia clínica, por exemplo, são indispensáveis na opção por condutas diagnósticas e terapêuticas na medicina contemporânea. A busca de evidências na literatura médica pode, ao informar o clínico acerca da eficácia e riscos ligados a determinados procedimentos, permitir decisões sobre uma menor base de incerteza. O que não quer dizer que a decisão mais fundamentada em evidências seja a melhor possível em uma situação particular.

Apontamos neste texto para algumas questões de caráter epistemológico, acerca do alcance do cálculo de probabilidades e seu poder de inferência, e da pertinência da proposição de uma "Medicina baseada em evidência" (Evidence-Based Medicine Working Group, 1992), bem como da aplicação da probabilidade bayesiana e nebulosa na clínica. Gostaríamos, no entanto, de concluir problematizando a dimensão ética. Que fatores estariam implicados nesta redução do julgamento à dimensão da informação de base estatística-probabilística?

Nossas reflexões no campo da Filosofia da Ciência ligadas à área da saúde norteiam-se pela possibilidade da aproximação de questões éticas e metodológicas. Para evidenciar a perspectiva escolhida, julgamos necessário explicitar a definição de "fato científico" utilizada.

De acordo com a interpretação dada por Popper à filosofia de Kant, é necessário ao conhecimento racional aceitar, a priori, a hipótese de que existe uma realidade exterior e inde- 
pendente do sujeito que a conhece. Hipótese metafísica, refratária a qualquer tipo de tentativa de refutação: ou se aceita, como pressuposto, um real que excede o sujeito que o conhece, ou perde o sentido a questão de um tipo de conhecimento a ser legitimado pelo método científico. A possibilidade do conhecimento objetivo repousaria, então, na aceitação a priori de um princípio não justificável empiricamente. Isto é fundamental para o entendimento da idéia de fato empírico que aqui pretendemos exprimir.

Para a ciência contemporânea, "fato" exprime-se num "enunciado observacional" (Popper, 1993) que pode ser deduzido de outro enunciado, mais geral, universal e categórico, elaborado com base na fundamentação teórica. Para tanto, torna-se necessária a construção de um outro tipo de enunciado, intermediário, que trata das coordenadas espaço-temporais do suposto fato empírico; de uma hipótese "Todo A é B", deduz-se o enunciado de especificação: "Se numa dada região $k$ do espaço e num certo momento t existir um objeto do tipo A, então este terá a propriedade de tipo B". Trata-se de uma dedução cujo objetivo é o de introduzir as variáveis de espaço e tempo, o que daria a condição de possibilidade ao experimento. $\mathrm{O}$ enunciado observacional ou factual seria deduzido do de especificação, apresentando-se como "existencial", isto é, do tipo "Há aqui um objeto ...". Para Popper, a pesquisa empírica deve satisfazer a esta exigência; a de que o enunciado observacional ou básico seja fruto de uma dedução. Isto dá a garantia de que a observação do fato acontece à luz da teoria universal. Aqui o filósofo austríaco tenta demonstrar que a ciência não pode ser o resultado de uma coleção de observações particulares. Assim, o enunciado existencial independente do universal não passa de observação particular, da qual jamais poderá ser deduzida uma boa inferência causal. De fato, sucessivas observações do tipo "há aqui um objeto do tipo A que tem a propriedade B" não levam necessariamente à conclusão de que o objeto A é causa da propriedade B. Não mais do que a inferência de que o canto do galo é causa do amanhecer. Nunca é demais voltar à Hume e à máxima de que a inferência causal excede a empiria. Então, como compatibilizar observação e inferência causal a não ser pelo que Hume chamara "hábito", mecanismo eficiente do ponto de vista prático, mas que escapa da fundamentação do racionalismo crítico popperiano.

Cabe aqui uma problematização simultaneamente ética e epistemológica: se escolhas são delegadas a softwares, entendemos que o são porque as concepções que temos de ciência e pesquisa científica, técnica e aplicação de tecnologias são constitutivas de nossa subjetividade. Deve-se problematizar o fato de a pesquisa em epidemiologia, por exemplo, que envolve inúmeras dimensões requerendo a participação - para além das ciências básicas e estatística - das ciências humanas e sociais, pareça escapar da fundamentação teórica, da busca de novas teorias e modelos, contentando-se com o exercício cotidiano da resolução de puzzles da ciência normal (Kuhn, 1978), circunscrevendo o debate "metodológico" à procura de desenhos de estudo mais adequados e à aplicação de tal ou qual pacote estatístico. A necessidade de uma revisão conceitual neste campo parece apresentar-se, para alguns epidemiologistas, como evidência. Mas há um irrefutável argumento utilitário e as decisões baseadas no resultado de estudos rigorosos e trabalhos de metanálise, tanto em saúde pública, como no cuidado individual, são desejáveis. $\mathrm{O}$ que pensar de uma ciência que se exerce como um contínuo acúmulo e tratamento estatístico de dados?

Popper parece ser o primeiro a construir um certo racionalismo no qual o a priori por si só não define o que é conhecimento. Aqui é original com relação à Kant. A razão é especulativa, por isso não pode ser povoada por categorias estáveis, fundadoras de um conhecimento seguro. O problema da causalidade, para citar uma das categorias vitais do entendimento, transforma-se radicalmente com Popper. A causa deixa de ser inferência para e passa a ser da ordem da conjectura, da hipótese. Isto se materializa no enunciado universal e categórico do tipo “Todo A é B”. Aqui há uma reviravolta na forma de a razão produzir seus fundamentos. O a priori de Popper é simplesmente conjectural. A causa, longe de ser conhecimento seguro, é uma especulação. Mas somente assim não fica resolvido o problema da fundamentação. Se a razão especula $a$ prio$r i$, em que solo repousará o conhecimento que vai além da simples opinião? Dito de outro modo, haverá algum sentido em acreditar na possibilidade de um conhecimento seguro? Popper responde que sim, mas a solução por ele proposta parece-nos escapar da necessidade da prova. A diferença entre ciência e pseudociência não está na capacidade que a primeira tem de valer-se de uma razão inequívoca, como quiseram Descartes e Kant, embora este último de forma não dogmática. Tampouco se assenta num puro empirismo em que observações legítimas justificariam a passagem do particular para o geral, num salto que vai além do 
que permitiria a lógica formal. A diferença entre ciência e pseudo-ciência deve ser buscada no tipo de diálogo que uma e outra travam com a natureza. $\mathrm{O}$ pensamento deve dialogar com o mundo de coisas e estados de coisas, de forma a extrair deste um testemunho. Esta é a base empírica do pensamento de Popper que parece, em um certo sentido, ter influenciado Stengers na definição do modo de produção, no diálogo experimental, de um "testemunho fidedigno”. A capacidade de fazer os fatos falarem de forma fidedigna, base da ciência moderna, estaria menos em função de critérios metódicos protocolares, absolutos, do que na “arte" do cientista em eleger um problema, elaborar uma pergunta pertinente e, valendo-se desta, uma hipótese teórica que nortearia o experimento (Stengers, 1995). Isabelle Stengers fala em um "Popper ético", cujo principal feito estaria na descrição do comportamento do cientista como eminentemente crítico e atento às possibilidades de refutação de sua hipótese pela natureza: convocada, mas jamais constrangida a falar (Stengers, 1995). Assim, sendo a ciência um exercício permanentemente críti-

\section{Referências}

BERNSTEIN, P., 1996. Against the Gods: The Remarkable Story of Risk. New York: John Wiley \& Sons.

CANGUILHEM, G., 1994. Etudes d'Histoire et de Philosophie des Sciences. Paris: Vrin.

DU PASQUIER, G., 1926. Le Calcul des Probabilités: Son Évolution Mathématique et Philosophique. Paris: Librairie Scientifique J. Hermann.

EVIDENCE-BASED MEDICINE WORKING GROUP, 1992. Evidence-based medicine: A new approach to teaching the practice of medicine. JAMA, 268: 2420-2425.

FLETCHER, R. H.; FLETCHER, S. W. \& WAGNER, E. H., 1996. Epidemiologia Clínica: Elementos Essenciais. Porto Alegre: Artes Médicas.

GUERREIRO, M., 1999. Ceticismo ou Senso Comum? Porto Alegre: EdPUCRS. co, o problema da pertinência evidencia-se. Que investigações seriam, num dado contexto, as mais pertinentes? E ainda, quais as táticas mais adequadas para tais investigações? A questão da pertinência não é restrita ao campo científico, mas envolve toda a sociedade. As relações entre ciência e poder apresentam-se aí em toda a sua vitalidade.

No privilegiamento da técnica, ao reduzir o diálogo experimental a trabalhos de aplicação e avaliação tecnológica, estamos nos arriscando duplamente: em uma dimensão metodológica, a uma volta ao empirismo ingênuo, como se fosse possível a existência de fato científico sem teoria, e na dimensão ética quando, ao desprezarmos a possibilidade de criticar os modelos atuais, deixamos de abrir espaço para soluções melhores, construindo um tipo de discurso auto-referente.

Uma alternativa seria utilizar as técnicas matemáticas como amplificadores de nossa percepção, uma informação a mais nas pesquisas e decisões clínicas, ao invés de permitir que os bancos de dados falem e prescrevam autonomamente.
HACKING, I., 1995. The Taming of Chance. Cambridge: University Press.

KANT, I., s/d. Crítica da Razão Pura. Lisboa: CalousteGulbenkian.

KUHN, T., 1978. A Estrutura das Revoluções Científicas. São Paulo: Perspectiva.

LEVY, H. \& ROTH, 1936. Elements of Probability. Oxford: University Press.

PLATÃO, 1996. Platão - Vida e Obra. São Paulo: Nova Cultural.

POPPER, K., 1993. A Lógica da Pesquisa Científica. São Paulo: Cultrix.

PRIGOGINE, I. \& STENGERS, I., 1992. A Nova Aliança. Brasília: Editora da Universidade de Brasília.

STENGERS, I., 1995. L'Invention des Sciences Modernes. Paris: Flammarion. 